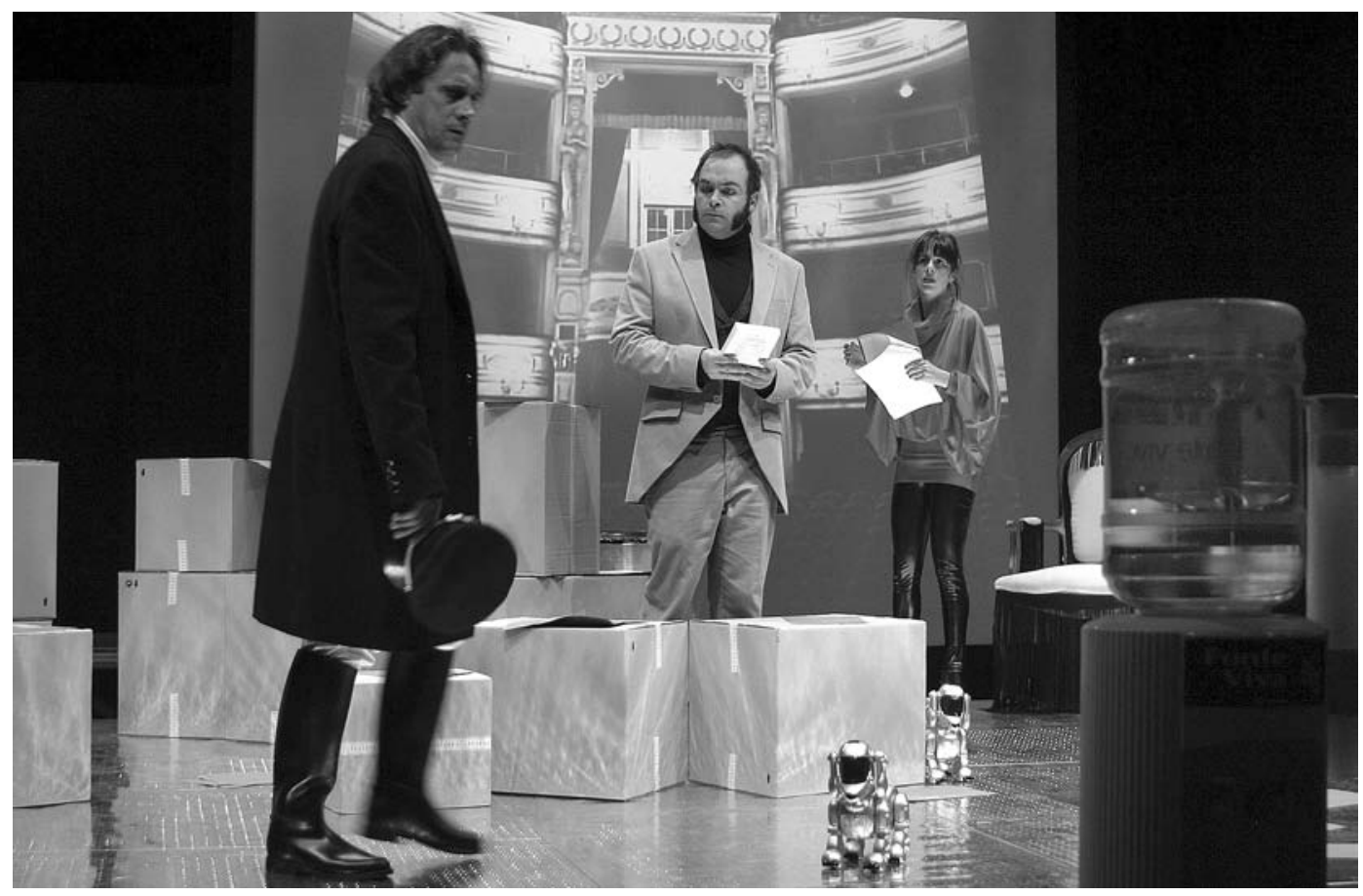

\title{
Performance e direitos de autor(a)
}

\section{Francesca Rayner}

Titulo: After Darwin (1998). Autor: Timberlake Wertenbaker. Tradução:Fernando Paz (a partir de versão de Osvaldo Mendes). Encenação: Carlos António. Cenografia e figurinos: Daniela Roxo. Desenho de luz: Carlos Arroja. Interpretação: André Levy, Manuel Coelho, Rita Calçada Bastos. Produção: Teatro Nacional D. Maria II. Local e data de estreia: Teatro da Politécnica, 12 de Dezembro de 2007.

Millie: A evolução não explica o gesto suicida.

lan: É uma boa definição de ir ao teatro.

Timberlake Wertenbaker, After Darwin

Não deixa de ser algo irónico, sobretudo numa peça que trata de questões relacionadas com a responsabilidade social de trabalhar com os outros, que esta recensão crítica comece precisamente com a observação de que esta produção se encontra algo distante do texto original escrito por Timberlake Wertenbaker. Apesar da aparente colagem do título ao original em língua inglesa, a produção corta completamente não só com a narrativa gay que atravessa toda a peça, mas também com a sua única personagem afro-americana. Ironicamente, Lawrence, esta personagem afro-americana é um dramaturgo, o que acaba por reforçar dramaticamente a excisão do texto de Wertenbaker da presente produção. Os responsáveis pela adaptação da peça têm todo o direito de efectuar os cortes de modo a tornar o texto mais representável e, em simultâneo, de aculturar a peça a um público português, nomeadamente através da alteração dos nomes dos actores da peça para "Manuel" e "André". No entanto, a decisão de pura e simplesmente retirar todo o mais vasto contexto político e social da peça parece-nos, no entanto, bem menos defensável. Poder-se-á, contudo, alegar, por certo, que a adaptação pretendia privilegiar o debate científico que coloca em confronto o transgressivo Darwin face ao conformismo religioso de FitzRoy. Desta forma, a peça insere-se dentro do "género" cada vez mais popular de "divulgação científica", pelo qual o Teatro da Politécnica é conhecido. Porém, esta estratégia não só demonstra uma grande condescendência face ao público que assiste a essas peças, ao sugerir que apenas poderão ver a ciência como algo "heterossexual" e "branco", como também acaba por tornar incompreensiveis alguns elementos da produção. 0 twist no final da peça, nomeadamente onde o mais velho dos dois actores destrói a carreira do mais novo através de uma acção casualmente chocante, acaba por perder muito do seu impacto social ao afectar irremediavelmente a sua ligação com o tema do HIV-SIDA. De igual forma, a ausência da surpreendente defesa feita por Lawrence do actor mais novo, com base na experiência partilhada de marginalização, acaba por transformar André numa personagem marcadamente ingénua e não propriamente alvo de contradição.

Na verdade, este facto revela-se ainda mais frustrante, sobretudo porque a escolha desta peça específica de Timberlake Wertenbaker é bastante interessante. Duas das peças desta dramaturga já foram anteriormente levadas à cena em Portugal, nomeadamente 0 romper do dia (The Break of Day, 1995), em 2001 no Teatro da Trinidade INATEL (tradução de Luisa Costa Gomes e Miguel Tamen), e Novas anatomias (New Anatomies, 1981), um intrigante retrato da viajante e aventureira Isabelle Eberhardt, pela Escola de
Francesca Rayner é Professora da Universidade do Minho. 

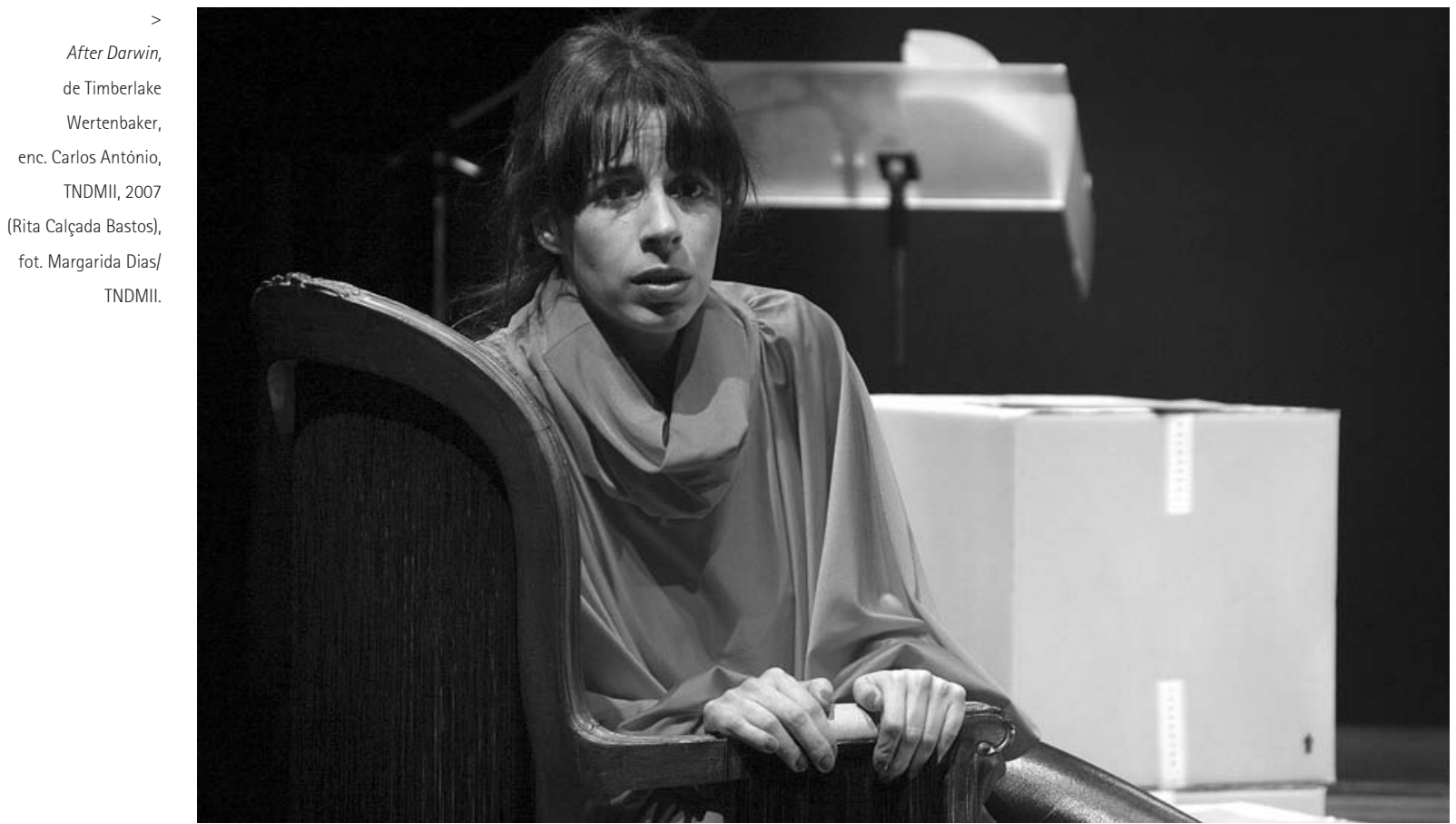

Mulheres - Oficina de Teatro, em 2002 (tradução de Fernanda Lapa e Isabel Medina). Wertenbaker é uma dramaturga e tradutora anglo-americana que escreveu uma série de peças bastante diversificadas e bem urdidas em termos de representação teatral durante as décadas de 80 e 90, a mais famosa das quais é Our Country's Good (1988). After Darwin (1998) é uma peça centrada em torno da representação de uma peça acerca de Charles Darwin e do seu conflito com Robert FitzRoy, o comandante do navio Beagle, a bordo do qual Darwin deu os primeiros passos rumo à formulação da sua teoria da evolução. Esta peça é representada por dois actores: um cuja carreira está em queda, mas que se mostra empenhado em trabalhar única e exclusivamente no teatro (Manuel Coelho), e o outro, um actor mais jovem, absolutamente indiferente ao facto de trabalhar no teatro, no cinema ou na televisão, desde que compense (André Levy). 0 debate científico sobre a evolução é, por isso mesmo, colocado numa posição de paralelismo em relação a um debate cultural sobre o declínio da noção do actor de teatro e a maior ascensão e protagonismo do performer de carácter generalista. A terceira personagem é Millie (Rita Calçada Bastos), a encenadora búlgara imigrante, para quem a peça é uma hipótese de poder finalmente conquistar o reconhecimento profissional e a possibilidade de permanecer no pais.

A produção é bem encenada, com uma utilização boa do espaço cénico e da iluminação. As cenas entre FitzRoy e Darwin dominam a produção e fornecem uma forte sensação de um crescente conflito entre os dois homens, à medida que Darwin rejeita o apelo de FitzRoy para reflectir sobre as implicações sociais e religiosas decorrentes da publicação do seu trabalho sobre a origem das espécies. As perspectivas dos dois homens recebem o mesmo peso dramático e os seus diálogos em palco são bastante claros em termos daquilo que está no centro dessa dicotomia. As cenas entre os dois actores são mais curtas e estabelecem um paralelismo entre a adaptação biológica e cultural de forma algo pesada, embora os actores, que desempenham estes papéis, transmitam a noção de que o conflito sobre se o individuo se deverá dedicar exclusivamente ao teatro ou se, pelo contrário, deverá aproveitar ao máximo o actual capital cultural composto por filmes e televisão, se encontra ilustrado através da diferença entre um estilo de representação mais realista e contemporâneo, associado a André, e um estilo mais antiquado e declamatório, associado a Manuel.

A decisão de incorporar as indicações cénicas da peça de forma a fazerem parte do papel de Millie é uma estratégia eficaz, acabando por dar um papel de maior relevo à actriz e criando a noção de que a peça está a ser construída à frente do público. No entanto, muitas vezes, a caracterização de Millie ultrapassa a transmissão de um sentido de urgência nessa outsider para cair na histeria. Assim, o bom trabalho na criação de um sotaque coerente em português para a personagem acaba por ser desvirtuado pela tendência para a gritaria na interpretação da actriz, o que, por vezes, faz com que as suas palavras sejam difíceis de entender pelo público. 0 único momento da representação em que a actriz reduz a estridência da sua interpretação, quando Millie revela inesperadamente um conhecimento outrora insuspeito acerca de Darwin e do seu trabalho a Manuel, ilustra a forma como teria sido possivel criar uma personagem feminina menos unidimensional, capaz de contrabalançar as duas interpretações masculinas.

Mesmo quem esteja familiarizado com o debate entre FitzRoy e Darwin acaba por achar esta produção interessante, uma vez que o conflito entre os dois consegue gerar um bom efeito dramático. De igual forma, para quem estiver preocupado com o futuro do teatro no contexto actual e intermedial, a produção acaba por encenar um debate cultural bem contemporâneo capaz de levantar mais perguntas do que respostas. No entanto, esta posição deverá sempre ser complementada pela leitura da peça na integra (embora, infelizmente, não exista qualquer tradução da peça actualmente disponivel) de forma a recordar-nos que, para que o teatro possa sobreviver no futuro, deverá exactamente assumir o mesmo tipo de riscos que esta produção não assumiu. 